\title{
Antibiotics don't cure toothache...
}

\author{
Stephen Hancocks OBE \\ Editor-in-Chief
}

The BDJ Upfront section includes editorials, letters, news, book reviews and interviews. Please direct your correspondence to the News Editor,

Kate Quinlan at BDJNews@nature.com. Press releases or articles may be edited, and should include a colour photograph if possible.

A nd neither do dentists. Don't panic, I'm not having a go, I'm just being pedantic. We don't cure toothache, we treat it and in doing so we aim to cure the symptoms. I think that's correct but a host of emails, tweets and maybe letters written on typewriters with chipped characters from around the world will soon correct me if I am wrong.

Why is this leap towards being niggly important? Because antimicrobial resistance is important and because although the overall story is well known to us the methods of actually reducing antibiotic prescribing require some precision, thought and practicality all of which have a complex interrelationship. We have touched on this topic several times in the past and as European Antibiotic Awareness Day falls on 18 November, this year is no different. Except it is, because a new resource called the Antimicrobial Stewardship Toolkit (AMS Toolkit) is being launched to help us all tackle the life changing effects of the declining ability of these pharmaceuticals to combat infections.

The Toolkit includes a patient poster (included as an insert in this issue of the $B D J$ ) and leaflets, an audit tool for use in clinical practice and resources of advice and guidance available via various websites.

In the UK, dentists represent about 10\% of the prescribing of antibiotics so one might be forgiven for taking the stance that this is a drop in a much larger ocean. Yet, typical of our approach to such matters we like to solve problems and we like to make a positive difference. Consequently, the Toolkit and the huge amount of work behind it and behind the move to reduce the extent of antibiotic prescribing has been done by dentists for dentists. It has been created as a collaboration between the BDA, the Faculty of General Dental Practice, Public Health England and a cohort of other dentally-related organisations. If that sounds familiar then it should. Without being over selfcongratulatory we should take credit for these initiatives which can only serve as a shining example to spur on other prescribers in human and veterinary medicine and in agriculture to undertake similar initiatives.

In essence the AMS Toolkit aims to help in two ways; patient education and creating a practice audit. Captured in the headline 'antibiotics don't cure toothache' is the nub of a problem with which we are all too familiar on a routine basis. Patients in pain want relief and want it quickly. That is human nature. The missing part of the logic here is the mistaken and long-harboured belief that antibiotics can do this - when you and I know that they cannot, at least in the overwhelming majority of cases. So best interests that must be paramount and ultimately that is a matter of conscientious decision by the individual clinician.

A second element of the Toolkit is the guidance in the process of undertaking a clinical audit into antibiotic prescribing (www.bda.org/amr and www.fgdp.org.uk). The majority of us will be very familiar with such activity which broadly requires assessing activity either retrospectively by use of records or prospectively by use of recording new data, analysing it, putting changes into action, measuring the effect of those changes and assessing their value. Yes, it is another 'thing to do' and it could be argued that we all have more than enough 'things to do' already but this one is clearly of huge importance for individuals, for dentistry and potentially for

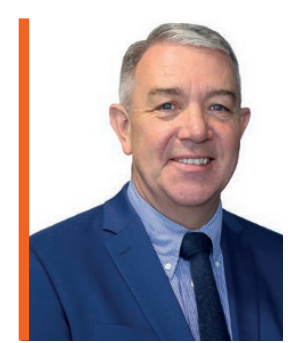

\section{'Patients in pain want relief and want it quickly. That is human nature...'}

what is needed is patient education. This has already begun in the wider world of colds and 'flu, where some progress has been made in public awareness. It may be that the acute nature of toothache makes people err towards the panic of 'I don't care about the science just get me out of pain' and so it may be that we have a longer job on our hands than in other disciplines where pain is not quite as great a factor in consulting a professional. What is certain is that others are watching our progress since the matter of informed consent is once again crucial here. Dentolegal, General Dental Council and NHS Performer issues in relation to appropriate prescribing therefore lurk in the wings. Crucially, it is always the patient's the future health of humanity; and we don't get to say that very often do we?

Prophetically in 1945 Sir Alexander Fleming warned that the 'public will demand [antibiotics] ... and then will begin.... an era of abuses'. Those wise words are now coming to fruition a in way that perhaps not even he could have anticipated but contained in which we have a duty to be guardians. Public education directly and increased awareness and information through audit will help in this movement. Paper and electronics do not cure antibiotic resistance but the knowledge that they generate enables us to treat patients appropriately and hopefully retain the power of antimicrobial medicines for as long as possible.

DOI: 10.1038/sj.bdj.2016.841 